The integration and stimulation of geophysical work in Canada are desirable for several reasons : (i) geophysical methods of mineral and oil prospecting have assumed great importance, and this will continue; (ii) the Pre-Cambrian shield is the biggest and richest area of basement rocks in the world, and its study will throw light on earth structure as well as provide minerals; (iii) there are large areas of potentially useful oil-bearing rocks in western Canada; (iv) no other country is in so interesting a position geophysically, since Canada includes the north magnetic pole, and extends to the north geographic pole, and nearly to the magnetic axis ; a larger part of the maximum auroral belt crosses Canada than any other country; (v) ionospheric studies for radio prediction have increased greatly during the War, and there are seven Canadian stations; the auroral belt will always produce peculiar effects; (vi) magnetic observations are lacking in northern Canada, where they are of value for navigation and of great interest near the magnetic pole.

More than a score of projects have already been initiated and further investigations are planned. One of the most fruitful subjects aided by the Committee has been the development of an airborne magnetometer. Fluxgate magnetometers were built by the National Research Council during the War; but these, it was known, would require extensive modifications before they could be adapted. to airborne use. An early type was fitted to aeroplanes flying on Exercise Musk-Ox, in order to gain experience. In the United. States, the Geological Survey had succeeded in adapting to geological use the magnetic airborne detector used in anti-submarine work, and it was thought this instrument would be suitable for use in Canada. The National Research Council obtained three sets from the United States Navy and modified them so that they will be available to the Department of Mines and Resources for use in Canada during the summer of 1947. Arrangements were made for a United States Geological Survey crew to bring a magnetometer to Canada and to make trial magnetic surveys of part of the Sudbury basin and of Louvicourt township. These surveys have been calculated, and the results will be published by the Geological Survey of Canada in co-operation with the United States Geological Survey.

In another project, mining and prospecting companies in Canada have co-operated with the Committee by supplying plans of magnetic readings for some of their properties. The Bourlamagne region in Quebec was chosen as a suitable area on which a regional map might be prepared from the magnetic survey data supplied by mining companies. Magnetic data for five townships have now been compiled and contoured. Comparison with the geology of the area will be made in a report now being prepared for publication.

A seismic study of the crust of the earth using rock-bursts as a source is projected for this season.

Geophysical work will continue to be done and paid for by existing departments, companies, and universities; but all this work will now be coordinated by the Associate Committee on Geodesy and Geophysics of the National Research Council. The Committee's work will not overlap that of the Geophysical Committee of the Geology Division of the Canadian Institute of Mining and Metallurgy, which deals with matters such as assessment laws, customs and tax rates, methods of procedure and professional ethics.
Steps have been taken to hold open meetings of the Associate Committee on Geodesy and Geophysics, the first of which was in connexion with the annual meeting of the Canadian Institute of Mining and Metallurgy at the National Research Building in Ottawa on January 23, 1947. The Committee proposes also to start publishing a bibliography on Canadian geophysics which will include reports on its activities.

\section{RELAXATION METHODS APPLIED TO ENGINEERING PROBLEMS}

$\mathrm{I}^{\mathrm{N}}$ $\mathrm{N}$ this latest instalment* of Dr. R. V. Southwell's application of his relaxation method for the solution of the differential equations of physics, the problems treated are of a kind which are particularly intractable by classical methods-problems relating to the flow of a fluid having one or more free surfaces in a gravitational field. In addition to their practical interest, the results obtained present in an acute form the fundamental question of the extent to which the numerical approach can disprove the possibility of a particular type of solution.

When the relaxation method reveals the existence of a hitherto mathematically unknown flow pattern (as it does in this paper in connexion with the wakes formed by entrained air behind a cylinder or sphere travelling through a fluid), it can be shown that this solution satisfies all the required conditions, and is therefore authentic. But when the computation fails to reveal the existence of a solution which on general grounds might be expected to exist, to what extent is it proved that no such solution does in fact exist? Such a case arises in this paper in the treatment of the stream-line distribution caused by the passage of an inclined plane of infinite width over the surface of a fluid of finite depth. Apparently, in this two-dimensional problem it is impossible for the depth of the fluid to be the same before and after the passage of the plane-a result which may appear to be contrary to expectation. Perhaps the best approach to this question is to regard the relaxation method as an experimental rather than as a mathematical technique. The authors repeatedly stress the tentative nature of the relaxation process, and perhaps their results can be seen in the proper perspective if they are regarded as experiments carried out, as real experiments so seldom are, under ideal mathematical conditions. The failure of such an experiment to reveal a certain phenomenon does not disprove its existence; but a sufficient number of such experiments, carried out under various conditions, and all giving a negative result, may be taken as demonstrating that the phenomenon does not occur in practice-which for the engineer is equivalent to a disproof of its possibility.

The paper also contains numerical solutions to a number of other problems, including the well-known case of the circular weir-Borda flow in three dimen. sions. From the point of view of computational technique, these problems are among the most difficult that have been attempted by relaxation, and the authors are to be congratulated on the successful conclusion of what must have been a formidable volume of arithmetic.

D. G. Christopherson by Free Stream-lines", by Dr. R. V. Southwell, F.R.S., and G. Vaisey. 